\title{
Hyper-Cross-Linked Polystyrene as a Stabilizing Medium for Small Metal Clusters
}

\author{
Alexey V. Bykov ${ }^{1}$, Galina N. Demidenko ${ }^{1}$, Linda Zh. Nikoshvili ${ }^{1, * \mathbb{D}}$ and Lioubov Kiwi-Minsker ${ }^{2,3, *}$ \\ 1 Department of Biotechnology, Chemistry and Standardization, Tver State Technical University, \\ A. Nikitina str. 22, 170026 Tver, Russia; bykovav@yandex.ru (A.V.B.); xt345@mail.ru (G.N.D.) \\ 2 Regional Technological Centre, Tver State University, Zhelyabova str. 33, 170100 Tver, Russia \\ 3 Department of Basic Sciences, Ecole Polytechnique Fédérale de Lausanne, ISIC-FBS-EPFL, \\ CH-1015 Lausanne, Switzerland \\ * Correspondence: nlinda@science.tver.ru (L.Z.N.); lioubov.kiwi-minsker@epfl.ch (L.K.-M.); \\ Tel.: +7-904-005-7791 (L.Z.N.); +41-21-693-3182 (L.K.-M.)
}

Citation: Bykov, A.V.; Demidenko, G.N.; Nikoshvili, L.Z.; Kiwi-Minsker, L. Hyper-Cross-Linked Polystyrene as a Stabilizing Medium for Small Metal Clusters. Molecules 2021, 26, 5294. https://doi.org/10.3390/ molecules26175294

Academic Editors: Raisa V. Talroze and Eugene Terentjev

Received: 26 July 2021

Accepted: 30 August 2021

Published: 31 August 2021

Publisher's Note: MDPI stays neutral with regard to jurisdictional claims in published maps and institutional affiliations.

Copyright: (c) 2021 by the authors. Licensee MDPI, Basel, Switzerland. This article is an open access article distributed under the terms and conditions of the Creative Commons Attribution (CC BY) license (https:// creativecommons.org/licenses/by/ $4.0 /)$.

\begin{abstract}
Among different polymers nanostructured cross-linked aromatics have the greatest potential as catalytic supports due to their exceptional thermal and chemical stability and preservation of the active phase morphology. This work studies the ability of hyper-cross-linked polystyrene (HPS) to stabilize small $\mathrm{Pd}_{\mathrm{n}}$ and $\mathrm{Pt}_{\mathrm{n}}(n=4$ or 9$)$ clusters. Unrestricted DFT calculations were carried out for benzene (BZ) adsorption at the BP level of theory using triple-zeta basis sets. The adsorption of BZ rings (stepwise from one to four) was found to result in noticeable gain in energy and stabilization of resulting adsorption complexes. Moreover, the interaction of metal clusters with HPS micropores was also addressed. For the first time, the incorporation of small clusters in the HPS structure was shown to influences its geometry resulting in the stabilization of polymer due to its partial relaxation.
\end{abstract}

Keywords: palladium; platinum; clusters; hyper-cross-linked polystyrene; benzene adsorption

\section{Introduction}

The development of new hybrid catalytic systems is of high importance, since it can lead to significant increases in the efficiency of catalytic reactions. Active centers formed in a polymeric environment combine the advantages of both homogeneous (selectivity, activity) and heterogeneous (easy separation) catalysts. Depending on the types of catalytically active metal and of polymeric support, the catalytic properties of such systems can be readily tuned.

Highly porous hyper-cross-linked aromatic polymers (HAP) presenting high mechanical, thermal and chemical stability are commercially available [1]. Such amorphous microporous polymers are promising for catalysis [2], e.g., as supports for both Pd complexes and $\mathrm{Pd}^{0}$ nanoparticles (NPs) [3-7] due to their high specific surface area, developed porosity and dual hydrophilic-hydrophobic character [7-12]. At the same time, functional groups on the polymer enhance the metal dispersion, and the specific porous structure ensures fast diffusion of reactants to the active centers. The distinctive feature of HAP is the simplicity of their production and relatively low price. Also due to the variety of available monomers, the pore sizes can be controlled and varied [13-15]. It is important to underline that the control of HAP porosity is crucial for high efficiency of the resulting catalyst and is achieved by sufficient chemical cross-linking, which prevents the collapse of polymeric chains into a dense non-porous material $[16,17]$.

During the last decades the interest of both the industrial and scientific communities in hyper-cross-linked polystyrene (HPS) has greatly increased. This is because of its advantages over traditional macroporous resins and activated carbons in terms of higher sorption capacity and easy regeneration [18]. Due to its high degree of cross-linking, which can exceed $100 \%$, the HPS consists of rigid nanovoids ("nanopores") serving as nanoreactors for metal particle growth [19-21]. 
Recently we have found that small $\operatorname{Pd}_{n}(n \leq 13)$ clusters can be also formed by the XPS method on the HPS surface along with $\mathrm{Pd}^{0} \mathrm{NPs}$ [22]. It is well known that HPS is an effective stabilizing medium for $\mathrm{Pd}^{0} \mathrm{NPs}$, even used for complex reactions such as Suzuki cross-coupling, which involve homogeneous stages in the catalytic cycle [23]. However, the role in cross-coupling reaction of small $\mathrm{Pd}_{\mathrm{n}}$ clusters formed during the preliminarily catalyst activation with gaseous hydrogen is still unclear: either they possess catalytic activity, or they just serve as a depot for active metal; either they influence the polymer properties (e.g., thermal and mechanical stability), or remain inert in the HPS micropores. To answer these questions, first the strength of interaction needs to be found, i.e., the energy of the adsorption of the small metal clusters ( $\mathrm{Pd}$ and $\mathrm{Pt}$ ) on the aromatic rings of HPS. It is important to determine also the mutual influence of metal clusters and polymeric chains.

The dynamic nature of catalytically active species has become evident in heterogeneous catalysis [24-27]. However, there are no direct instrumental methods to assess small metal clusters immobilized on supports, and hence, mechanistic studies are necessary. DFT modeling is widely used to describe polymers and metal clusters [28-32]. Many works describe DFT modeling of $\mathrm{Pd}_{\mathrm{n}}$ clusters [33-36] as well as adsorption of different compounds on them [37-39]. Duca et al. [40] have calculated the geometry of HPS and $\mathrm{Pd}_{\mathrm{n}}$ $(n \leq 9)$ clusters using the CAM-B3LYP functional joined with the LANL2-DZ basis set and found that hosting HPS deforms when Pd atoms are added to growing cluster. The balance between the Pd-C and the Pd-Pd interactions was shown to be crucial, and $\mathrm{Pd}_{4}$ is on the borderline. At the same time it was proposed that the benzene (BZ) rings of HPS allow stabilization of $\mathrm{Pd}_{\mathrm{n}}$ clusters, and small cavities in HPS structure affect both the geometric and the electronic properties of Pd clusters [40]. Nevertheless, there is still lack of data on the interaction of HPS and small metal clusters, i.e., the energy of adsorption of polymer $\mathrm{BZ}$ rings on $\mathrm{Pd}$ and Pt clusters.

Carneiro et al. [41] have studied BZ adsorption on Pd and Pt clusters using B3LYP/ LANL2DZ. For the most stable triplet state of the $\mathrm{Pd}_{7}$ cluster the energy of $\mathrm{BZ}$ adsorption was found to be about $26-29 \mathrm{kcal} / \mathrm{mol}$. It is noteworthy that B3LYP is the most popular density functional [36-41], which fits well for geometry optimization. At the same time, it was mentioned [42] that B3LYP is not fully suitable for energetic calculations. Hence some authors $[42,43]$ preferred PBE functional. In order to resolve the issue of the functional choice, we performed calculation of $\mathrm{BZ}$ adsorption on $\mathrm{Pd}_{4}$ cluster in a triplet state while using several available exchange-correlation functionals (Figure S1). We have found that BP functional provides values of the adsorption energy close to the results of temperatureprogrammed desorption of $\mathrm{BZ}$ adsorbed on $\mathrm{Pd}(111)[44,45]$, and also fits well some other reported results $[43,46,47]$.

This work studies the interaction of immobilized small Pd and Pt clusters with the HPS micropores, and the degree of micropore deformation during the cluster adsorption. Thus, for the first time, in the framework of this work we carried out DFT modeling of BZ adsorption (both free $\mathrm{BZ}$ rings and $\mathrm{BZ}$ of HPS micropore) on small clusters of $\operatorname{Pd}_{n}(n=4$ or 9) and $\mathrm{Pt}_{4}$ using $\mathrm{BP}$ functional. As a result the adsorption energies of $\mathrm{BZ}$ rings on $\mathrm{Pd}$ and $\mathrm{Pt}$ clusters were calculated, helping in the analysis of real catalytic experiments over HAP impregnated by noble metals. It is noteworthy that some works has studied small Pd clusters confined in the HPS [40], but the stabilization of the microporous polymeric network by metal clusters has been never revealed. For the first time the difference between $\mathrm{Pt}_{4}$ and $\mathrm{Pd}_{4}$ stabilized into the HPS micropores was shown.

\section{Results}

Unrestricted DFT calculations were carried out at the BP level of theory for small metal clusters $\left(\mathrm{Pd}_{4}, \mathrm{Pd}_{9}, \mathrm{Pt}_{4}\right.$, and $\left.\mathrm{Pt}_{9}\right)$ and the adsorption of one, two, three and four $\mathrm{BZ}$ rings on them, as well as for the adsorption of these clusters in the model HPS micropore to study the stabilization of palladium and platinum clusters in aromatic polymeric networks. 


\subsection{Adsorption of Aromatics on $P d_{n}$ Clusters}

The results of the calculations of the ground state of palladium clusters are presented in Table 1 and Figure 1.

Table 1. Results of geometry and relative energy calculations for $\mathrm{Pd}_{4}$ and $\mathrm{Pd}_{9}$.

\begin{tabular}{cccccc}
\hline & $\mathbf{P d}_{\mathbf{4}}$ & \multicolumn{3}{c}{$\mathbf{P d}_{\mathbf{9}}$} \\
\hline $\mathbf{2 S + 1}$ & $\mathbf{d E}(\mathbf{e V})$ & $\langle\mathbf{P d}-\mathbf{P d}>\mathbf{( \AA )}$ & $\mathbf{2 S + 1}$ & $\mathbf{d E}(\mathbf{e V})$ & <Pd-Pd $>(\AA)$ \\
\hline 1 & 0.452 & 2.59 & 1 & 0.215 & 2.65 \\
3 & 0.000 & 2.59 & 3 & 0.000 & 2.65 \\
5 & 1.082 & 2.58 & 5 & 0.049 & 2.57 \\
\hline
\end{tabular}

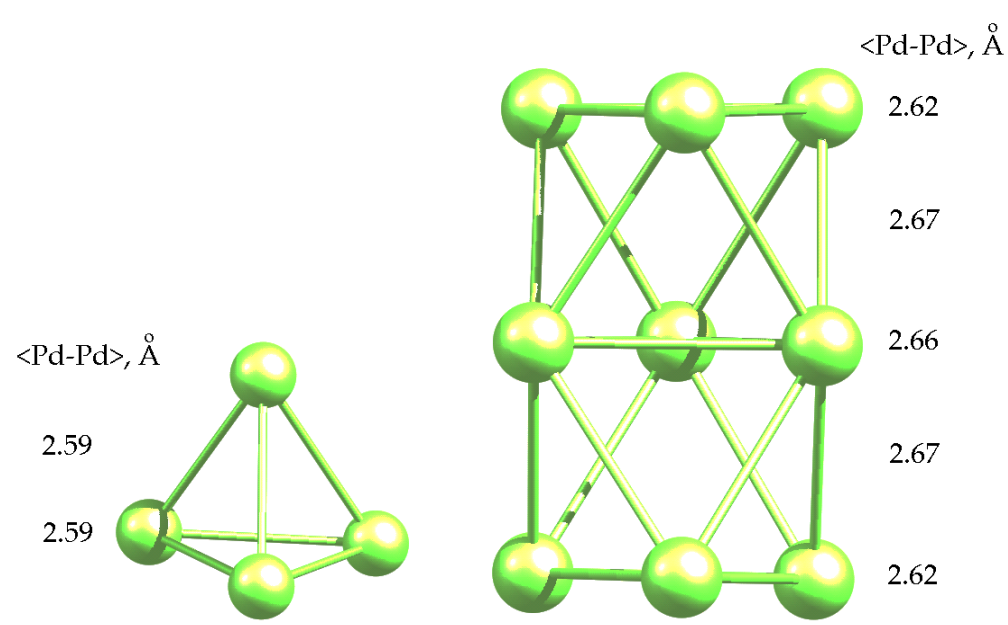

Figure 1. Optimized geometries of $\mathrm{Pd}_{4}$ and $\mathrm{Pd}_{9}$ clusters in a triplet state.

As it can be seen, triplet was the ground state for both clusters, which is in good agreement with the literature data [40-43]. The average $<\mathrm{Pd}-\mathrm{Pd}>$ bond lengths were $2.59 \AA$ and $2.65 \AA$ for $\mathrm{Pd}_{4}$ and $\mathrm{Pd}_{9}$ clusters, respectively. These values were used to estimate the changes in the bond lengths of clusters in adsorption complexes. It is noteworthy that in the structure of $\mathrm{Pd}_{4}$ cluster, which was a slightly distorted tetrahedron, two mutually non-intersecting edges had a length of $2.55 \AA$, while all the other edges had a length of $2.61 \AA$. Obviously, such a distortion was due to the Jahn-Teller effect. In the case of BZ adsorption on $\mathrm{Pd}_{4}$ clusters, the triplet was also shown to be the ground state (Table 2).

Table 2. Relative energies of $\mathrm{Pd}_{4}{ }^{*} \mathrm{C}_{6} \mathrm{H}_{6}$ and the energy of $\mathrm{BZ}$ adsorption on $\mathrm{Pd}_{4}$ for different states.

\begin{tabular}{ccc}
\hline $\mathbf{2 S}+\mathbf{1}$ & $\mathbf{d E}, \mathbf{e V}$ & $\mathbf{E}_{\mathbf{a d s}, \mathbf{~} \mathbf{~ J} / \mathbf{m o l}}{ }^{(\mathbf{1})}$ \\
\hline 1 & 0.263 & -164.1 \\
3 & 0.000 & -145.9 \\
5 & 2.126 & -45.2 \\
\hline
\end{tabular}

(1) calculated with respect to $\mathrm{Pd}_{4}$ of the same multiplicity.

Calculation of $\mathrm{Pd}_{4}$ adsorption complexes in the triplet state with one, two, three and four $\mathrm{BZ}$ molecules (Figure 2) has shown that $\mathrm{Pd}_{4}$ is able to coordinate all the four $\mathrm{BZ}$ rings: the adsorption energies in the series $\mathrm{Pd}_{4}{ }^{*} \mathrm{C}_{6} \mathrm{H}_{6}, \mathrm{Pd}_{4}{ }^{*} \mathrm{C}_{6} \mathrm{H}_{6}, \mathrm{Pd}_{4}{ }^{*} 3 \mathrm{C}_{6} \mathrm{H}_{6}$ and $\mathrm{Pd}_{4}{ }^{*} \mathrm{C}_{6} \mathrm{H}_{6}$ were $-145.9,-200.4,-256.6$ and $-286.1 \mathrm{~kJ} / \mathrm{mol}$, respectively. The adsorption of $\mathrm{Pd}_{4}$ with its base, consisting of three Pd atoms, on the first BZ ring led to the gain in energy of $-149.5 \mathrm{~kJ} / \mathrm{mol}$ (or $-48.6 \mathrm{~kJ} / \mathrm{mol}$ per each of the three Pd atoms). At the same time, the average $<\mathrm{Pd}-\mathrm{Pd}>$ bond length increased by $1.9 \%$ (Figure 2a). 


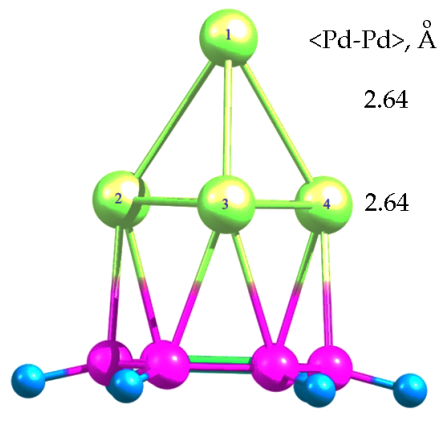

(a)

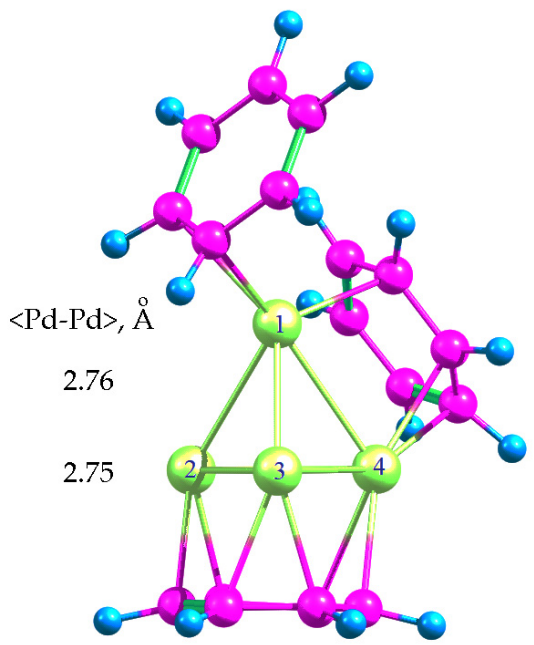

(c)

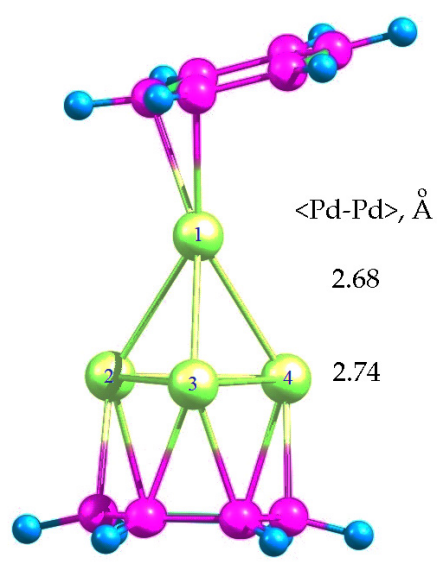

(b)

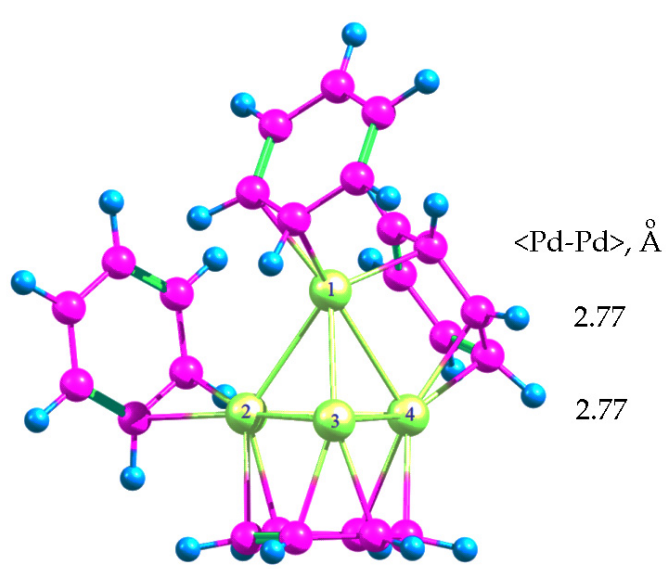

(d)

Figure 2. Optimized geometries of Pd-BZ adsorption complexes: $\mathrm{Pd}_{4}{ }^{*} \mathrm{C}_{6} \mathrm{H}_{6}(\mathbf{a}), \mathrm{Pd}_{4}{ }^{*} \mathrm{C}_{6} \mathrm{H}_{6}(\mathbf{b})$, $\mathrm{Pd}_{4} * 3 \mathrm{C}_{6} \mathrm{H}_{6}(\mathbf{c})$ and $\mathrm{Pd}_{4} * 4 \mathrm{C}_{6} \mathrm{H}_{6}(\mathbf{d})$.

The adsorption of the second and third $\mathrm{BZ}$ rings on $\mathrm{Pd}_{4}$ led to an energy gain of $-54.5 \mathrm{~kJ} / \mathrm{mol}$ and $-56.2 \mathrm{~kJ} / \mathrm{mol}$, respectively, due to $\mathrm{BZ}$ coordination with the single vertex Pd atom (Figure $2 \mathrm{~b}$ ) and also along the edge of the cluster with two Pd atoms already involved in coordination with other BZ rings (Figure $2 \mathrm{c}$ ). In the latter case, this corresponded to the change in energy of the system by $-28.1 \mathrm{~kJ} / \mathrm{mol}$ per each of two $\mathrm{Pd}$ atoms. Moreover, the coordination of the second and third BZ rings also resulted in the increase of the average $<\mathrm{Pd}-\mathrm{Pd}>$ bond length up to $2.71 \AA$ (Figure $2 \mathrm{~b}$ ) and $2.75 \AA$ (Figure 2c) for $\mathrm{Pd}_{4}{ }^{*} \mathrm{C}_{6} \mathrm{H}_{6}$ and $\mathrm{Pd}_{4}{ }^{*} 3 \mathrm{C}_{6} \mathrm{H}_{6}$, respectively. This corresponds to an increase of the average $<\mathrm{Pd}-\mathrm{Pd}>$ bond length by $4.6 \%$ and $6.2 \%$ as compared to free $\mathrm{Pd}_{4}$ cluster. It is noteworthy that the average $<\mathrm{Pd}-\mathrm{Pd}>$ distance between the atoms of base was greater than those for free $\mathrm{Pd}_{4}$ cluster by $5.6 \%\left(\right.$ in $\left.\mathrm{Pd}_{4}{ }^{*} \mathrm{C}_{6} \mathrm{H}_{6}\right)$ and $5.9 \%\left(\right.$ in $\left.\mathrm{Pd}_{4}{ }^{*} \mathrm{C}_{6} \mathrm{H}_{6}\right)$.

The adsorption of fourth BZ molecule led to an even greater expansion of the cluster: the average $<\mathrm{Pd}-\mathrm{Pd}>$ bond length increased up to $2.77 \AA$, which is by $7.0 \%$ higher than for the free cluster. In this case, the disproportion between the average $<\mathrm{Pd}-\mathrm{Pd}>$ distance of the vertex atom and $<\mathrm{Pd}-\mathrm{Pd}>$ distance of the base practically disappeared.

Coordination of palladium atoms belonging to $\mathrm{Pd}_{4}$ cluster with $\mathrm{BZ}$ rings caused partial transfer of electron density from palladium to carbon (Table 3) and its redistribution to $\pi$-electron density of aromatic ring (see also Figure S2). 
Table 3. Löwdin charges of $\mathrm{Pd}_{4}$ and Pd-BZ adsorption complexes.

\begin{tabular}{cccccc}
\hline $\begin{array}{c}\text { Location (Sequential } \\
\text { Number of Pd Atom) }\end{array}$ & $\mathbf{P d}_{\mathbf{4}}$ & $\mathbf{P d}_{\mathbf{4}}{ }^{*} \mathbf{C}_{\mathbf{6}} \mathbf{H}_{\mathbf{6}}$ & $\mathbf{P d}_{\mathbf{4}}{ }^{*} \mathbf{2}_{\mathbf{6}} \mathbf{H}_{\mathbf{6}}$ & $\mathbf{P d}_{\mathbf{4}}{ }^{*} \mathbf{3 C}_{\mathbf{6}} \mathbf{H}_{\mathbf{6}}$ & $\mathbf{P d}_{\mathbf{4}}{ }^{*} \mathbf{4} \mathbf{C}_{\mathbf{6}} \mathbf{H}_{\mathbf{6}}$ \\
\hline vertex (1) & 0.000 & 0.056 & 0.042 & 0.044 & 0.057 \\
base (2) & 0.000 & 0.058 & 0.103 & 0.135 & 0.142 \\
base (3) & 0.000 & 0.058 & 0.100 & 0.113 & 0.124 \\
base (4) & 0.000 & 0.057 & 0.098 & 0.154 & 0.161 \\
\hline
\end{tabular}

As a next step, the geometry of $\mathrm{Pd}_{9}{ }^{*} \mathrm{C}_{6} \mathrm{H}_{6}$ adsorption complex (Figure $3 \mathrm{a}$ ) and the adsorption energy of BZ molecule on free $\mathrm{Pd}_{9}$ cluster were calculated. The adsorption energy of $\mathrm{BZ}$ on $\mathrm{Pd}_{9}$ was found to be $-97.4 \mathrm{~kJ} / \mathrm{mol}$, i.e., the energy of $\mathrm{BZ}$ adsorption decreased with the increase of cluster size. The electron density was also transferred from $\mathrm{Pd}_{9}$ to the carbons of BZ (Figure $3 \mathrm{~b}, \mathrm{c}$ ).

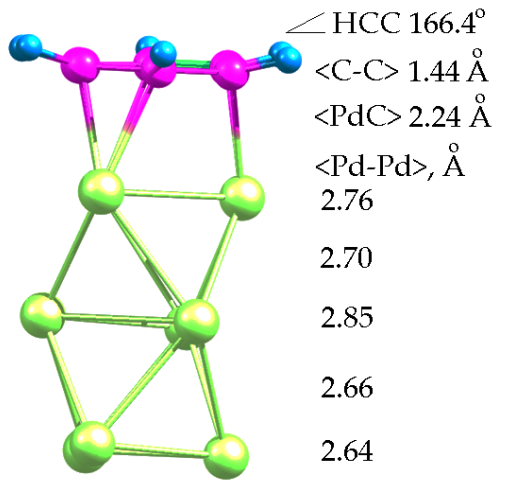

(a)

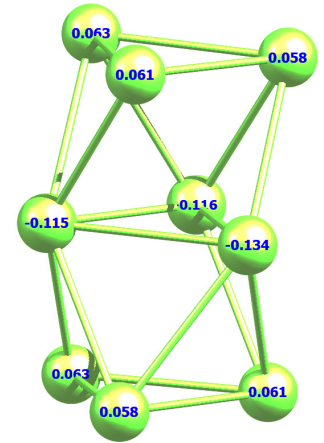

(b)

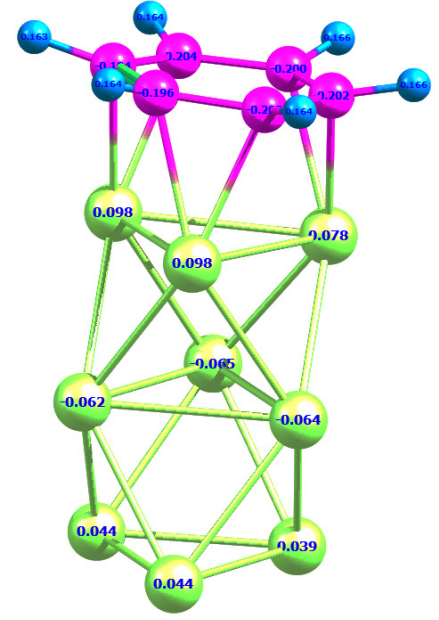

(c)

Figure 3. Optimized geometry of $\mathrm{Pd}_{9}{ }^{*} \mathrm{C}_{6} \mathrm{H}_{6}$ adsorption complex (a) and Löwdin charges of $\operatorname{Pd}_{4}(\mathbf{b})$ and $\mathrm{Pd}_{9}{ }^{*} \mathrm{C}_{6} \mathrm{H}_{6}(\mathbf{c})$.

Based on the results obtained, it is possible to assume that $\mathrm{Pd}_{4}$ clusters while being in their ground state are able to coordinate BZ molecules and to be stabilized in the aromatic environment. This fact can serve as a reference point for evaluating and comparing the efficiency of the interaction between palladium clusters and the polymer micropores. It is known that noble metal clusters confined in polymers are too large to be investigated by using first principle calculations [32]. Hence it is common practice to replace whole polymers with similar smaller molecules. To study the possibility of stabilization and to find the adsorption energy of $\mathrm{Pd}_{4}$ cluster in the HPS network, a model micropore, which is formed by the fragments of polystyrene chains whose BZ rings are cross-linked with methylene bridges, as well as the adsorption complex of $\mathrm{Pd}_{4}$ cluster in this pore, were calculated at the same level of theory. In each case, the entire structure was allowed to relax during the optimization. The calculated structures are shown in Figure 4.

The adsorption energy was found to be $-237.3 \mathrm{~kJ} / \mathrm{mol}$ (or $-59.3 \mathrm{~kJ} / \mathrm{mol}$ per each palladium atom), which is quite close to the adsorption energy of three $\mathrm{BZ}$ molecules on a $\mathrm{Pd}_{4}$ cluster. The average $<\mathrm{Pd}-\mathrm{Pd}>$ bond length was increased by $6.2 \%$ as compared to a free $\mathrm{Pd}_{4}$ cluster that coincides with the change of bond length for $\mathrm{Pd}_{4}{ }^{*} 3 \mathrm{C}_{6} \mathrm{H}_{6}$ system.

The slight decrease of the adsorption energy of $\mathrm{Pd}_{4}$ in the polymer micropores as compared to the case of $\mathrm{BZ}$ adsorption on $\mathrm{Pd}_{4}$ was likely due to the limitations of the conformational mobility of the polymer linkages, which did not allow optimizing the geometry of the adsorption complex the same way as in the case of individual BZ rings. 


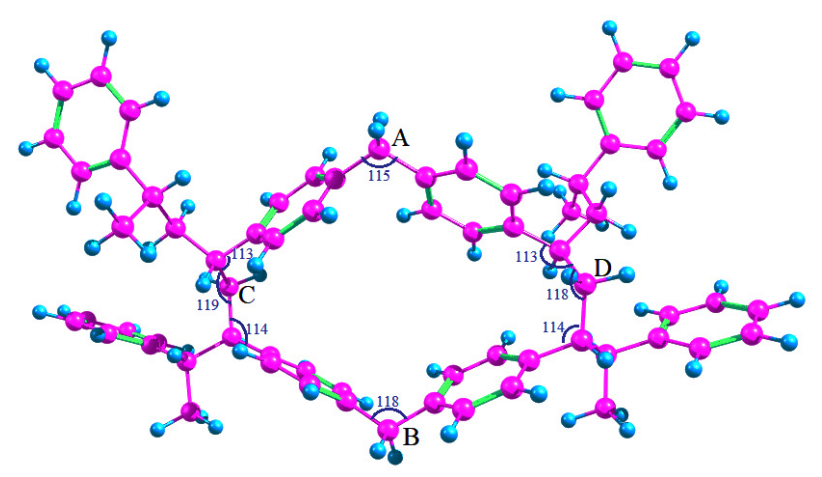

(a)

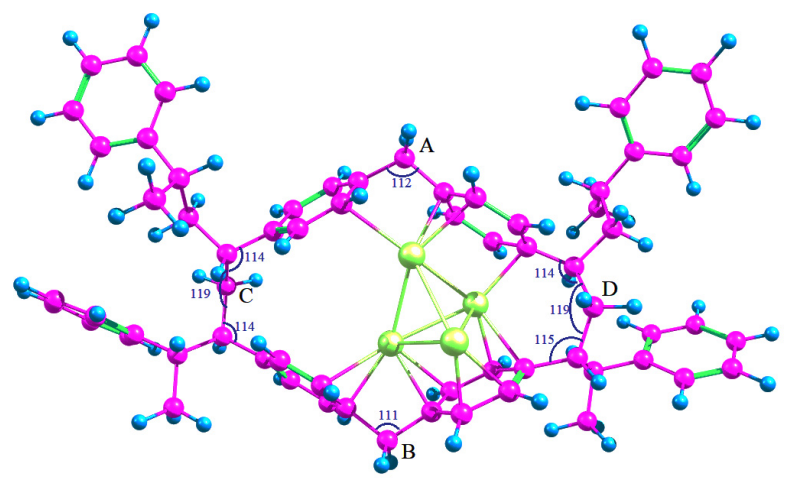

(b)

Figure 4. Optimized geometry of HPS micropore before (a) and after (b) incorporation of $\mathrm{Pd}_{4}$.

To determine the changes in geometry of the polymer micropores during the incorporation of $\mathrm{Pd}_{4}$ cluster, the methylene groups, indicated in Figure 4 as " $\mathrm{A}$ ", " $\mathrm{B}$ ", " $\mathrm{C}$ " and " $\mathrm{D}$ ", were selected. Obviously, the most significant changes in the pore structure occurred in the area of the cluster adsorption (Table 4 ) since $\mathrm{Pd}_{4}$ itself is much smaller than the pore and cannot fill completely the entire micropore. Incorporation of $\mathrm{Pd}_{4}$ resulted in the increase in the pore diameter (" $\left.\mathrm{AB}^{\prime \prime}\right)$ by $4.6 \%$, which is associated with the adaptation of the pore geometry during the coordination of $\mathrm{BZ}$ rings with the cluster. At the same time, the valence angles of covalent bonds of the methylene groups " $\mathrm{A}$ " and " $\mathrm{B}$ " decreased from $115^{\circ}$ and $118^{\circ}$ to $112^{\circ}$ and $111^{\circ}$, respectively, which indicates the decrease in pore tension (the angles tend to $109^{\circ} 28^{\prime}$, corresponding to $\mathrm{sp}^{3}$-hybridized carbon atoms). Significant changes in other distances ("BD" and "AD" by 3.4 and $2.1 \%$ ) are associated with conformational changes that do not affect the valence angles of methylene groups.

Table 4. Structure parameters of the polymer micropore in case of $\mathrm{Pd}_{4}$ incorporation.

\begin{tabular}{cccc}
\hline Distance, $\mathbf{A}$ & Polymer & Pd $_{\mathbf{4}}{ }^{*}$ Polymer & Change, $\mathbf{o}$ \\
\hline $\mathrm{AB}$ & 7.83 & 8.19 & 4.6 \\
$\mathrm{CD}$ & 10.72 & 10.90 & 1.7 \\
$\mathrm{AC}$ & 6.67 & 6.71 & 0.6 \\
$\mathrm{AD}$ & 6.71 & 6.85 & 2.1 \\
$\mathrm{BC}$ & 6.76 & 6.78 & 0.3 \\
$\mathrm{BD}$ & 6.75 & 6.98 & 3.4 \\
\hline
\end{tabular}

Incorporation of $\mathrm{Pd}_{9}$ (see Figure 1) into the same micropore caused dramatic restructuring of the cluster (Figure 5). The adsorption energy of $\mathrm{Pd}_{9}$ was $-341.2 \mathrm{~kJ} / \mathrm{mol}$, which was $44 \%$ higher than in the case of $\mathrm{Pd}_{4}$ incorporated into the same micropore. However, an average value of the adsorption energy calculated per each Pd atom was $-37.9 \mathrm{~kJ} / \mathrm{mol}$, which was $36 \%$ lower as compared to $\mathrm{Pd}_{4}$ stabilized in the same micropore $(-59.3 \mathrm{~kJ} / \mathrm{mol}$ per atom).

In the case of both $\mathrm{Pd}_{4}$ and $\mathrm{Pd}_{9}$, there was a shift in the electron density from palladium to $\mathrm{BZ}$ rings of the polymer (Figure 6 ).

It is noteworthy that the change in the pore geometry is directly associated with the removal of tension in the methylene bridges " $\mathrm{A}$ " and " $\mathrm{B}$ ": elongation of the pore along the " $\mathrm{AB}$ " direction by $14.8 \%$ (Table 5 ) and decrease of valence angles of the methylene groups " $\mathrm{A}$ " and "B (Figure 5) can be seen. 
Table 5. Structure parameters of the polymer micropore in case of $\mathrm{Pd}_{9}$ incorporation.

\begin{tabular}{cccc}
\hline Distance, $\AA$ & Polymer & Pd $_{\mathbf{9}}$ *Polymer & Change, $\mathbf{~}$ \\
\hline $\mathrm{AB}$ & 7.83 & 8.99 & 14.81 \\
$\mathrm{CD}$ & 10.72 & 10.32 & -3.73 \\
$\mathrm{AC}$ & 6.67 & 6.79 & 1.80 \\
$\mathrm{AD}$ & 6.71 & 6.91 & 2.98 \\
$\mathrm{BC}$ & 6.76 & 6.74 & -0.30 \\
$\mathrm{BD}$ & 6.75 & 6.93 & 2.67 \\
\hline
\end{tabular}

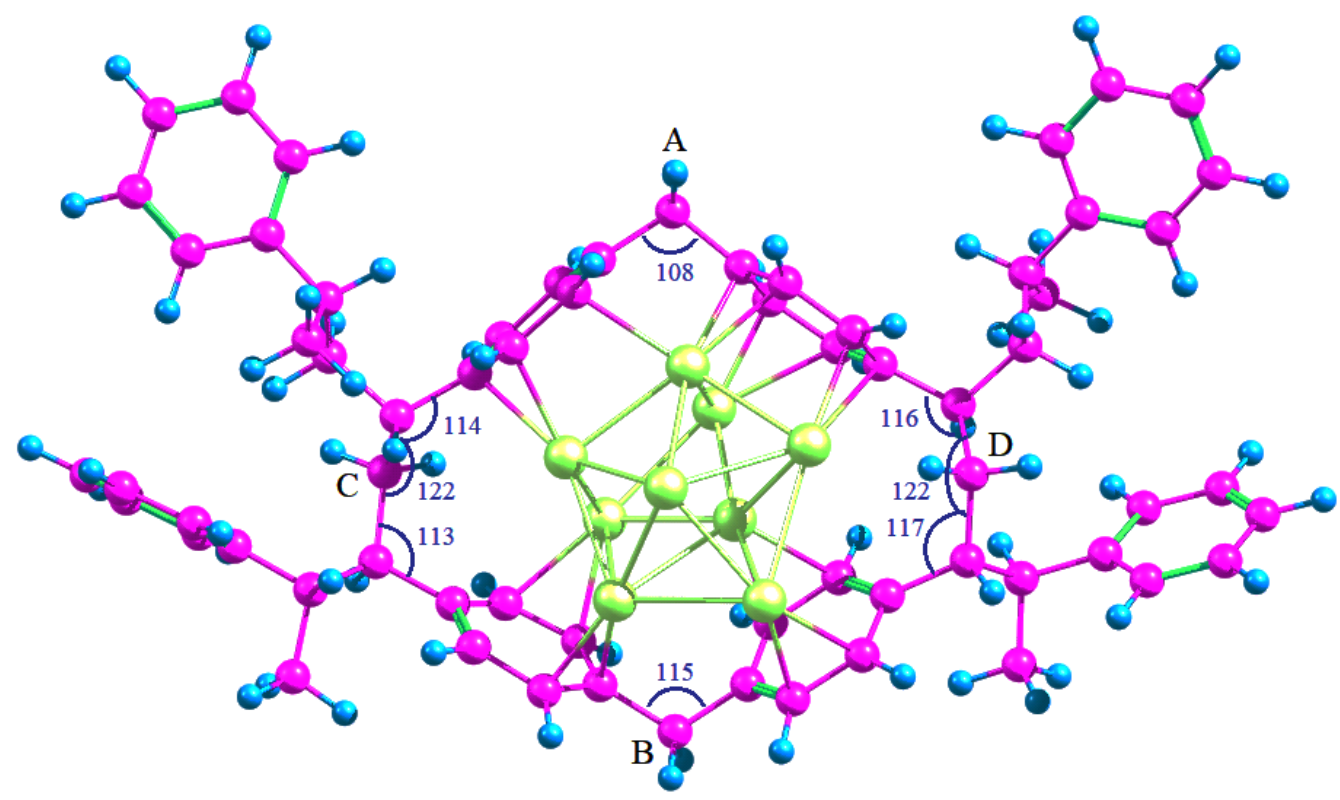

Figure 5. Optimized geometry of $\mathrm{Pd}_{9}$ incorporated into the HPS micropore.

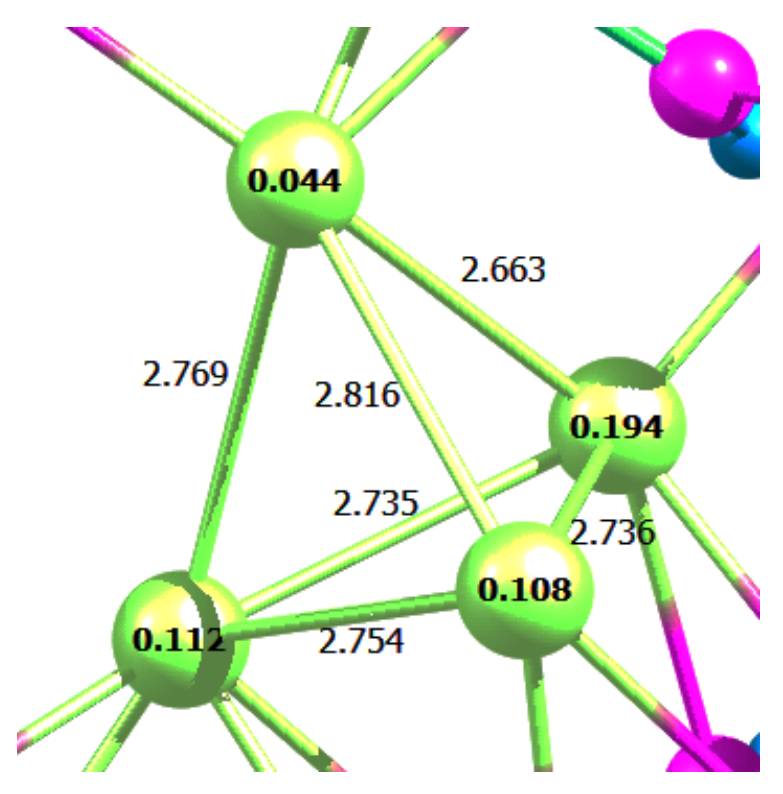

(a)

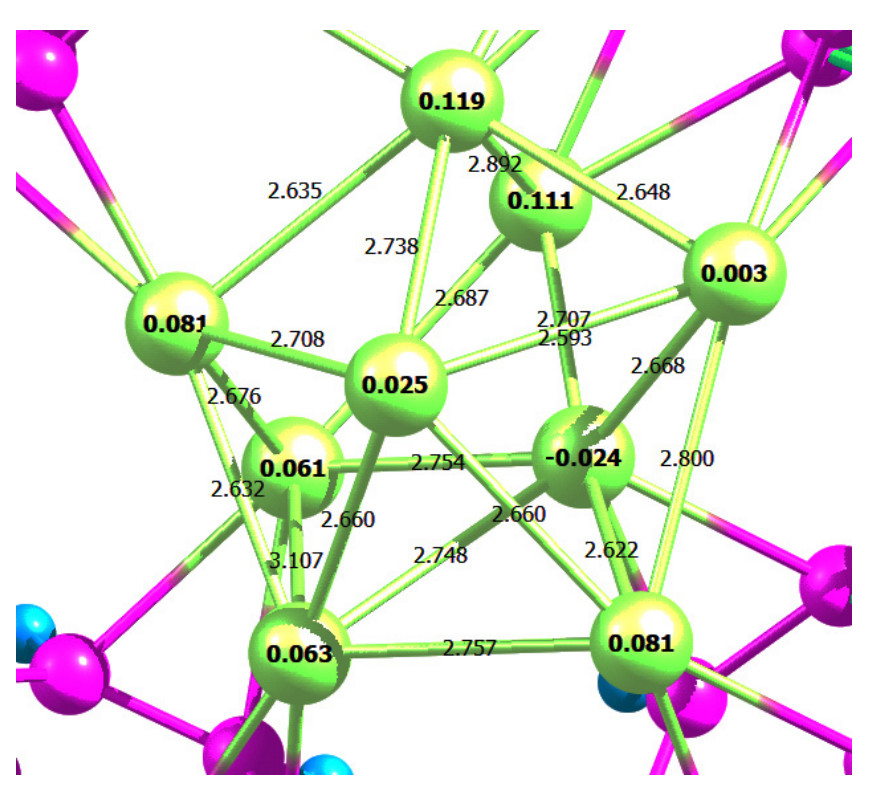

(b)

Figure 6. Löwdin charges and bond lengths for optimized polymer-stabilized $\mathrm{Pd}_{4}(\mathbf{a})$ and $\mathrm{Pd}_{9}(\mathbf{b})$. 


\subsection{Adsorption of Aromatics on $P t_{n}$ Clusters}

The results of calculation of the ground state of platinum clusters are presented in Table 6 and Figure 7. Similarly to the $\mathrm{Pd}_{\mathrm{n}}$ clusters, the triplet one was found to be the ground state for $\mathrm{Pt}_{4}$. The average $<\mathrm{Pt}-\mathrm{Pt}>$ bond length is $2.59 \AA$ and $2.65 \AA$ for $\mathrm{Pt}_{4}$ and $\mathrm{Pt}_{9}$ cluster, respectively. Moreover, the structure of $\mathrm{Pt}_{4}$ cluster was slightly distorted: one edge of tetrahedron had length of $2.69 \AA$, while all the other edges are $2.57-2.58 \AA$.

Table 6. Results of geometry calculations for $\mathrm{Pt}_{4}$ and $\mathrm{Pt}_{9}$.

\begin{tabular}{cccccc}
\hline & $\mathbf{P t}_{\mathbf{4}}$ & \multicolumn{5}{c}{$\mathbf{P t}_{\mathbf{9}}$} \\
\hline $\mathbf{2 S + 1}$ & $\mathbf{d E}, \mathbf{e V}$ & $\langle\mathbf{P t}-\mathbf{P t}\rangle, \mathbf{A}$ & $\mathbf{2 S + 1}$ & $\mathbf{d E}, \mathbf{e V}$ & $<\mathbf{P t}-\mathbf{P t}\rangle, \AA$ \\
\hline 1 & 0.496 & 2.61 & 1 & - & - \\
3 & 0.000 & 2.59 & 3 & 0.000 & 2.65 \\
5 & 0.038 & 2.58 & 5 & - & - \\
\hline
\end{tabular}

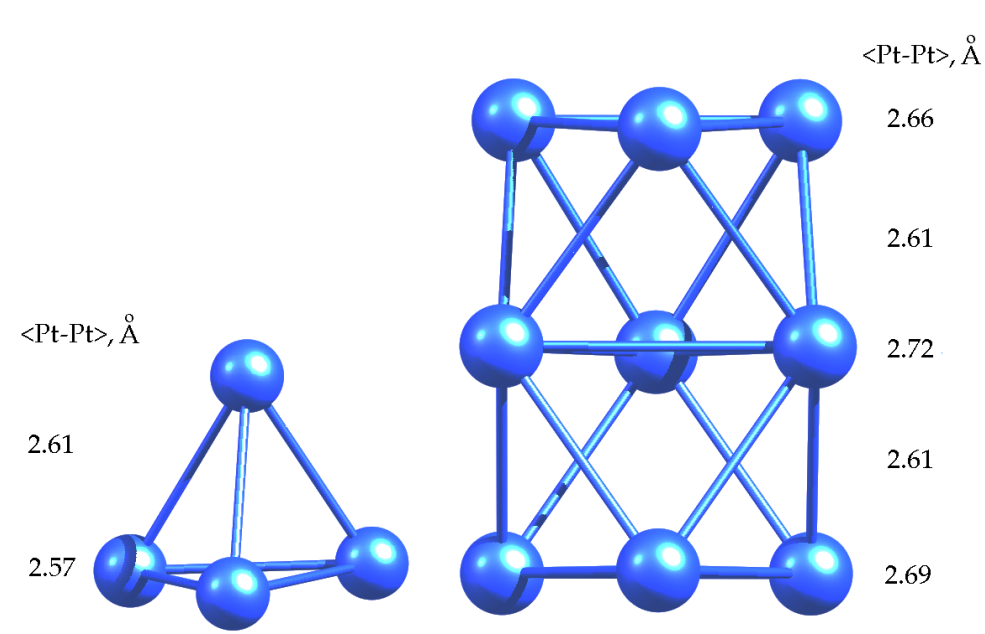

Figure 7. Optimized geometries of $\mathrm{Pt}_{4}$ and $\mathrm{Pt}_{9}$ clusters in a triplet state.

Similarly to $\mathrm{Pd}_{4}{ }^{*} \mathrm{C}_{6} \mathrm{H}_{6}$ (see Table 2), the triplet was the ground state in the case of $\mathrm{Pt}_{4}{ }^{*} \mathrm{C}_{6} \mathrm{H}_{6}$ (Table 7).

Table 7. Relative energies of $\mathrm{Pt}_{4}{ }^{*} \mathrm{C}_{6} \mathrm{H}_{6}$ and the energy of $\mathrm{BZ}$ adsorption on $\mathrm{Pt}_{4}$ for different states.

\begin{tabular}{ccc}
\hline $\mathbf{2 S}+\mathbf{1}$ & $\mathbf{d E}, \mathbf{e V}$ & $\mathbf{E}_{\mathbf{a d s}}, \mathbf{~} \mathbf{J} / \mathbf{m o l} \mathbf{~}^{\mathbf{1}}$ \\
\hline 1 & 0.392 & -240.6 \\
3 & 0.000 & -230.6 \\
5 & 1.145 & -123.8 \\
\hline
\end{tabular}

${ }_{1}^{1}$ calculated with respect to $\mathrm{Pt}_{4}$ of the same multiplicity

Calculation of $\mathrm{Pt}_{4}$ adsorption complexes in the triplet state with one, two, three and four BZ molecules (Figure 8) revealed that the adsorption energies in the series $\mathrm{Pt}_{4}{ }^{*} \mathrm{C}_{6} \mathrm{H}_{6}$, $\mathrm{Pt}_{4} * 2 \mathrm{C}_{6} \mathrm{H}_{6}, \mathrm{Pt}_{4} * 3 \mathrm{C}_{6} \mathrm{H}_{6}$ and $\mathrm{Pt}_{4} * 4 \mathrm{C}_{6} \mathrm{H}_{6}$ were $-230.6,-273.8,-387.6$, and $-463.0 \mathrm{~kJ} / \mathrm{mol}$, respectively. Thus the adsorption of $\mathrm{Pt}_{4}$ with its base on the first $\mathrm{BZ}$ ring led to the gain in energy of $-230.6 \mathrm{~kJ} / \mathrm{mol}$ (or $-76.9 \mathrm{~kJ} / \mathrm{mol}$ per each $\mathrm{Pt}$ atom). The average $<\mathrm{Pt}-\mathrm{Pt}>$ bond length increased by $1.5 \%$ (Figure $8 \mathrm{a}$ ).

The adsorption of the second and third $\mathrm{BZ}$ rings on $\mathrm{Pt}_{4}$ led to energy gains of $-43.2 \mathrm{~kJ} / \mathrm{mol}$ and $-113.8 \mathrm{~kJ} / \mathrm{mol}$, respectively. The second $\mathrm{BZ}$ ring was coordinated with the single vertex $\mathrm{Pt}$ atom (Figure $8 \mathrm{~b}$ ) similarly to $\mathrm{Pt}_{4}{ }^{*}{ }_{2} \mathrm{C}_{6} \mathrm{H}_{6}$ (Figure $2 \mathrm{~b}$ ), while the addition of the third $\mathrm{BZ}$ ring resulted in noticeable rearrangement of the coordination ensemble (Figure $8 \mathrm{c}$ ). At the same time the average $<\mathrm{Pt}-\mathrm{Pt}>$ bond length increased up to $2.71 \AA\left(\mathrm{Pt}_{4} * 2 \mathrm{C}_{6} \mathrm{H}_{6}\right)$ and to $2.65 \AA\left(\mathrm{Pt}_{4} * 3 \mathrm{C}_{6} \mathrm{H}_{6}\right)$, which corresponded to an increase of the average $<\mathrm{Pt}-\mathrm{Pt}>$ bond length by $4.6 \%$ and $2.1 \%$ as compared to free $\mathrm{Pt}_{4}$ cluster. The average 
$<\mathrm{Pt}-\mathrm{Pt}>$ distance between the atoms of base was greater than those for free $\mathrm{Pt}_{4}$ cluster by $6.6 \%$ (in $\mathrm{Pt}_{4}{ }^{*} \mathrm{C}_{6} \mathrm{H}_{6}$ ) and $2.3 \%$ (in $\mathrm{Pt}_{4}{ }^{*} 3 \mathrm{C}_{6} \mathrm{H}_{6}$ ). Such slight changes in $\langle\mathrm{Pt}-\mathrm{Pt}\rangle$ bond length in the case of $\mathrm{Pt}_{4}{ }^{*} 3 \mathrm{C}_{6} \mathrm{H}_{6}$ are likely due to the observed rearrangement of the ensemble.

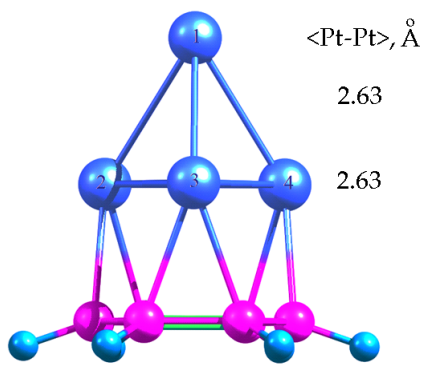

(a)

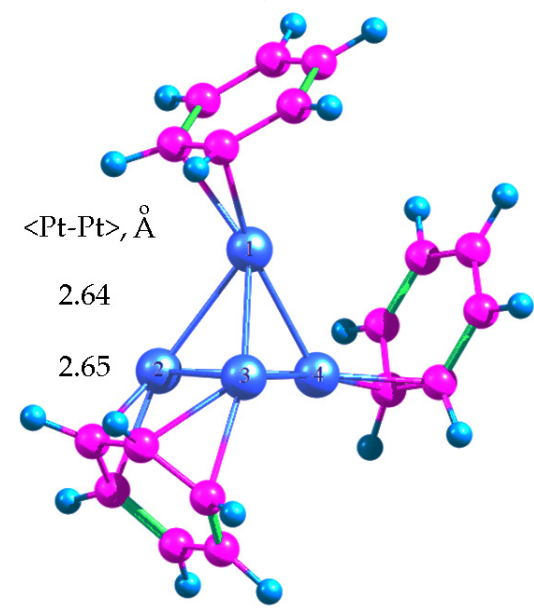

(c)

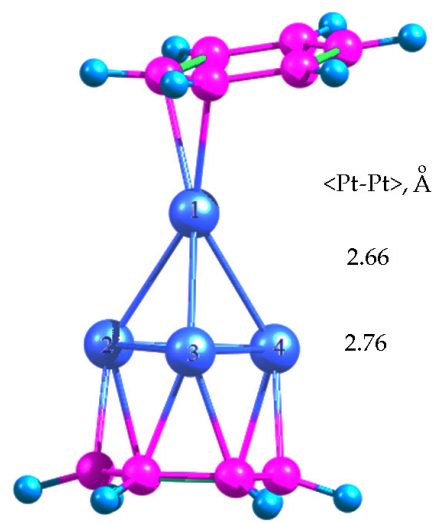

(b)

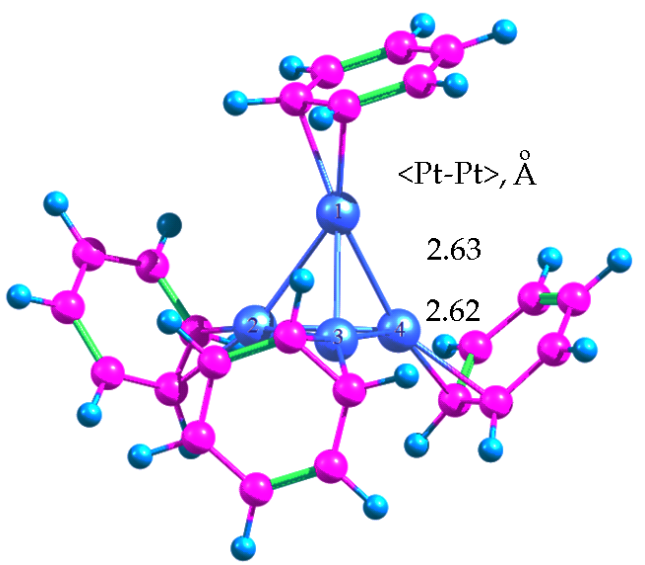

(d)

Figure 8. Optimized geometries of Pt-BZ adsorption complexes: $\mathrm{Pt}_{4}{ }^{*} \mathrm{C}_{6} \mathrm{H}_{6}(\mathbf{a}), \mathrm{Pt}_{4} * 2 \mathrm{C}_{6} \mathrm{H}_{6}$ (b), $\mathrm{Pt}_{4}{ }^{*} 3 \mathrm{C}_{6} \mathrm{H}_{6}(\mathbf{c})$ and $\mathrm{Pt}_{4}{ }^{*} 4 \mathrm{C}_{6} \mathrm{H}_{6}(\mathbf{d})$.

The adsorption of fourth BZ ring led to additional gain in energy by $-75.4 \mathrm{~kJ} / \mathrm{mol}$ and to slight compression of the cluster: the average $<\mathrm{Pt}-\mathrm{Pt}\rangle$ bond length in the adsorption complex $\mathrm{Pt}_{4}{ }_{4} 4 \mathrm{C}_{6} \mathrm{H}_{6}$ was $2.63 \AA$, which is only by $1.4 \%$ higher than for free $\mathrm{Pt}_{4}$ cluster and can be explained by the relatively symmetrical environment of the cluster by $\mathrm{BZ}$ rings.

In contrast to palladium, when the platinum atoms coordinated with BZ molecules, partial transfer of the electron density from carbon atoms to Pt occurred (Table 8) due to redistribution of $\pi$-electron density of BZ rings (see Figure S3). The higher the number of adsorbed $\mathrm{BZ}$ rings, the more electron density is transferred to a $\mathrm{Pt}_{4}$ cluster.

Table 8. Löwdin charges of $\mathrm{Pt}_{4}$ and Pt-BZ adsorption complexes.

\begin{tabular}{cccccc}
\hline $\begin{array}{c}\text { Location (Sequential } \\
\text { Number of Pt Atom) }\end{array}$ & $\mathbf{P t}_{4}$ & $\mathbf{P t}_{\mathbf{4}}{ }^{*} \mathbf{C}_{\mathbf{6}} \mathbf{H}_{\mathbf{6}}$ & $\mathbf{P t}_{\mathbf{4}}{ }^{*} \mathbf{C}_{6} \mathbf{H}_{\mathbf{6}}$ & $\mathbf{P t}_{\mathbf{4}}{ }^{*} \mathbf{C}_{\mathbf{6}} \mathbf{H}_{\mathbf{6}}$ & $\mathbf{P t}_{\mathbf{4}}{ }^{*} \mathbf{C}_{\mathbf{6}} \mathbf{H}_{\mathbf{6}}$ \\
\hline vertex (1) & 0.000 & -0.079 & -0.206 & -0.174 & -0.167 \\
base (2) & 0.000 & -0.278 & -0.106 & -0.112 & -0.160 \\
base (3) & 0.000 & -0.279 & -0.107 & -0.111 & -0.162 \\
base (4) & 0.000 & -0.279 & -0.102 & -0.178 & -0.164 \\
\hline
\end{tabular}


The possibility of stabilization of $\mathrm{Pt}_{4}$ cluster in the HPS micropore was also studied using the same model micropore as in the case of $\mathrm{Pd}_{\mathrm{n}}$ clusters (see Section 2.1) at the same level of theory. The calculated structure is shown in Figure 9. The adsorption energy was $-371.3 \mathrm{~kJ} / \mathrm{mol}$, which was slightly lower than in the case of $\mathrm{Pt}_{4}{ }^{*} 3 \mathrm{C}_{6} \mathrm{H}_{6}$ adsorption complex. Due to the fact that the adsorption energy of $\mathrm{BZ}$ rings on $\mathrm{Pt}_{4}$ cluster was relatively high, and the polymer pore had rather rigid structure with limited conformational mobility, complete restructuring of the cluster and its adaptation to the pore geometry was observed. The average value of $<\mathrm{Pt}-\mathrm{Pt}>$ bond length was $2.60 \AA$ at the significant transfer of electron density from the polymer to Pt (see the Löwdin charges in Figure 9).
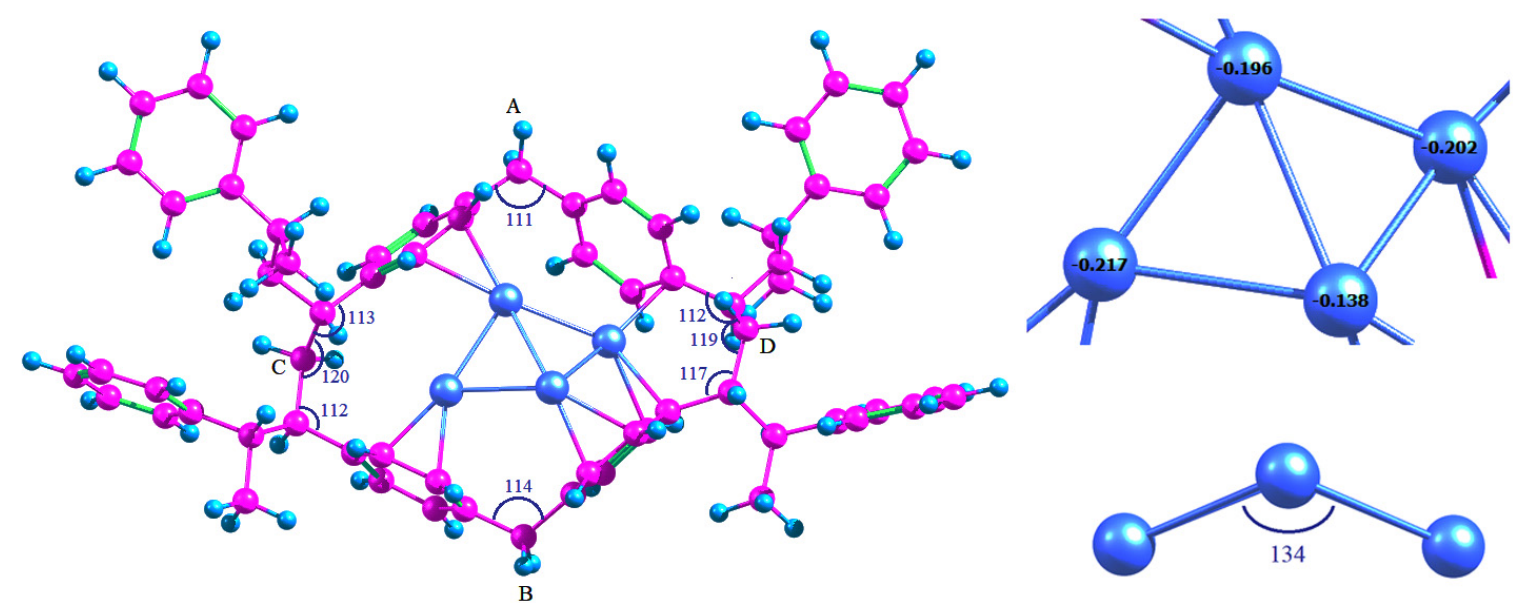

Figure 9. Optimized geometry of $\mathrm{Pt}_{4}$ incorporated into the HPS micropore and Löwdin charges of Pt atoms.

The pore itself was noticeably expanded in the direction of methylene groups " $\mathrm{A}$ " and "B" (Table 9): the distance "AB" increased by about $11 \%$. This also caused the decrease of tension of the methylene groups " $\mathrm{A}$ " and " $\mathrm{B}$ " since their valence angles decreased from $115^{\circ}$ and $118^{\circ}$ to $111^{\circ}$ and $114^{\circ}$, respectively. At the same time, some tension appeared in the methine radical located on the segment "BD" between the BZ ring and the methylene group " $\mathrm{D}$ ".

Table 9. Structure parameters of the polymer micropore in case of $\mathrm{Pt}_{4}$ incorporation.

\begin{tabular}{cccc}
\hline Distance, $\mathbf{A}$ & Polymer & Pt $_{\mathbf{4}}{ }^{*}$ Polymer & Change, $\mathbf{~}$ \\
\hline $\mathrm{AB}$ & 7.83 & 8.69 & 10.98 \\
$\mathrm{CD}$ & 10.72 & 10.39 & -3.08 \\
$\mathrm{AC}$ & 6.67 & 6.69 & 0.30 \\
$\mathrm{AD}$ & 6.71 & 6.78 & 1.04 \\
$\mathrm{BC}$ & 6.76 & 6.66 & -1.48 \\
$\mathrm{BD}$ & 6.75 & 7.07 & 4.74 \\
\hline
\end{tabular}

\section{Discussion}

DFT calculations of BZ adsorption (from one up to four rings) on the small $\mathrm{Pd}_{\mathrm{n}}$ and $\mathrm{Pt}_{\mathrm{n}}$ $(n=4)$ clusters were carried out at the BP level of theory, which allowed obtaining refined values of the adsorption energies serving as starting point for calculation of metal clusters interaction with the micropore of the aromatic polymer (HPS). It was shown that $\mathrm{Pd}_{4}$ and $\mathrm{Pt}_{4}$ clusters can be effectively stabilized due to the adsorption of BZ rings. Such adsorption leads to geometric distortions of the metal clusters as well as to charge redistribution between the clusters to their chemical environment. It was found for the first time that charge transfer in the case of palladium and platinum has contrary direction: in the case of $\mathrm{Pd}_{4}$ the partial transfer of electron density from the metal to carbon takes place, while in the case of $\mathrm{Pt}_{4}$, in contrary, the partial transfer of electron density occurs from carbon atoms of $\mathrm{BZ}$ rings to the metal. It is noteworthy that interaction of $\mathrm{Pt}_{4}$ cluster with $\mathrm{BZ}$ rings was 
stronger and caused higher gain in energy (the energy of adsorption complex $\mathrm{Pt}_{4}{ }_{4} 3 \mathrm{C}_{6} \mathrm{H}_{6}$ was $-273.8 \mathrm{~kJ} / \mathrm{mol}$ ) as compared to $\mathrm{Pd}_{4}$ (the energy of adsorption complex $\mathrm{Pd}_{4}{ }^{*}{ }^{3} \mathrm{C}_{6} \mathrm{H}_{6}$ was $-256.6 \mathrm{~kJ} / \mathrm{mol}$ ).

Clusters of both types $\left(\mathrm{Pd}_{4}\right.$ and $\left.\mathrm{Pt}_{4}\right)$ were found to be effectively stabilized in a model micropore of the polymer (HPS) calculated at the same level of theory. It was shown that the metal clusters can be captured by the HPS micropores and retained with a significant (essential for the purposes of heterogeneous catalysis) adsorption energies. The adsorption energy of $\mathrm{Pd}_{4}$ in the HPS micropore was $-237.3 \mathrm{~kJ} / \mathrm{mol}$, and the increase of $\mathrm{Pd}_{\mathrm{n}}$ cluster size up to $n=9\left(\mathrm{Pd}_{9}\right)$ resulted in the energy gain $(-341.2 \mathrm{~kJ} / \mathrm{mol})$, which confirms that the growth of small metal clusters in the aromatic polymeric environment is the energy beneficial process accompanied by the adaptation of clusters' geometry to the micropore structure. At the same time, in the case of platinum the interaction of Pt atoms with the BZ rings of the HPS micropore is so strong that it causes noticeable distortion of clusters' geometry even for $\mathrm{Pt}_{4}$.

Moreover, it was shown for the first time that the incorporation of small metal clusters into the HPS micropores changes the pores' geometry, which in turn decreases the methylene bridge (the cross-links of HPS) tension. Thus one can conclude that the noble metal clusters act as micropore stabilizers, which may prevent the polymer destruction during significant vibrations and pulsations of its chains. The latter can take place during high-temperature treatment of polymer-based composites. Such a treatment is commonly applied in heterogeneous catalysis as a part of the activation procedure, i.e., gas-phase reduction of catalysts in a hydrogen flow. Though it is not possible to directly assess small metal clusters buried in the pores of HAP, the results obtained in this study can be useful to explain behavior of real catalytic systems exposed to high-temperatures.

Finally, it can be concluded that the high adsorption ability of $\mathrm{Pd}_{4}$ and $\mathrm{Pt}_{4}$ clusters in the HPS polymeric network can lead to their deposition in micropores or small mesopores, which can have a strong impact on catalytic properties of such systems. While being stabilized in aromatic environment, small metal clusters can be inaccessible for reagents during heterogeneous catalytic reactions or alternatively they can play a role of buffer for catalytically active metal species. The interaction of metal clusters incorporated into micropores of HAPs with different catalytic substrates should be further studied and this work is in progress.

\section{Computational Methods}

The search for the level of theory for calculations was performed on the basis of calculations of the energy of $\mathrm{BZ}$ adsorption on $\mathrm{Pd}_{4}$ cluster in the triplet state. The adsorption energy was calculated by the unrestricted methods of Hartree-Fock, perturbation theory, as well as the DFT using B3LYP, PBE and BP functionals both with and without the ZORA formalism. The effect of the empirical van der Waals correction on the adsorption energy in the case of DFT was also tested. The results of calculations are presented in Figure S1. Since up to date there are no experimental data on the structure of palladium clusters and the adsorption energies of arenes on palladium clusters, the value of the adsorption energy of BZ on Pd (111) surface found from calorimetric studies [44] is one of few reliable sources of information for validation. This value $(-131 \mathrm{~kJ} / \mathrm{mol})$ was taken as a reference point. Based on the comparison of the obtained results and the impossibility of verifying the validity of the empirical van der Waals correction for the considered systems, all the presented studies were performed under conditions that better describe the experimental result.

All the DFT calculations were unrestricted and were performed using Orca 4.2.1 [48,49] package at the BP level of theory. The relativistic effects were taken into account by means of the ZORA formalism. For C and $\mathrm{H}$ the ZORA-def2-TZVP basis set was used [50], including with diffusion and polarized sets. In case of palladium, old-ZORA-TZVP basis set was used. In case of platinum, segmented all-electron relativistically contracted, SARC-ZORA-TZVP 
basis set was used. During each optimization, the entire structure was allowed to relax. Adsorption energies were calculated as follows:

$$
E_{a d s}=E_{A B n}-E_{A}-n E_{B}
$$

where $E_{A B n}$ is the energy of adsorption complex; $E_{A}$ is the metal cluster energy; $E_{B}$ is the energy of BZ.

\section{Conclusions}

In the framework of this study, BZ adsorption on small clusters of $\mathrm{Pd}_{\mathrm{n}}$ and $\mathrm{Pt}_{\mathrm{n}}$ ( $n=4$ or 9) was calculated at the BP level of theory. The adsorption of arenes (and BZ, in particularly) was previously studied in many works, but we obtained the adsorption energies for the metal cluster interactions with the polymer (HPS) chains at the same level of theory. For the purpose of catalysis the calculation of adsorption energies of noble metal clusters is of great importance as it can serve as a starting point for further calculations of reactants' adsorption and the migration of noble metals within polymeric networks. We have confirmed that the B3LYP functional, which was used in most previous works, not always provides accurate calculations in comparison with BP and PBE functionals. Thus, using the $\mathrm{BP}$ functional we compared for the first time the adsorption of $\mathrm{BZ}$ molecules on clusters of palladium and platinum, which allowed us to conclude that these metals behave differently in an aromatic environment, i.e., opposite charge transfer directions were found. Moreover, $\mathrm{Pt}_{4}$ clusters were found to undergo dramatic changes in geometry when encapsulated in the micropores of HPS. The stabilization of the polymer micropores by $\mathrm{Pt}$ and $\mathrm{Pd}$ clusters was also revealed for the first time, which represents a very important result for the preparation of heterogeneous polymer-based catalysts.

Supplementary Materials: The following are available online, Figure S1: Comparison of different calculation methods and basis sets for $\mathrm{Pd}_{4}{ }^{*} \mathrm{C}_{6} \mathrm{H}_{6}$ adsorption complex, Figure S2: Isosurfaces $0.06 \mathrm{e} / \AA^{3}$ of the adsorption complexes $\mathrm{Pd}_{4}{ }^{*} \mathrm{C}_{6} \mathrm{H}_{6}, \mathrm{Pd}_{4}{ }^{*} \mathrm{C}_{6} \mathrm{H}_{6}, \mathrm{Pd}_{4}{ }^{*} 3 \mathrm{C}_{6} \mathrm{H}_{6}$ and $\mathrm{Pd}_{4}{ }^{*} 4 \mathrm{C}_{6} \mathrm{H}_{6}$, Figure S3: Isosurfaces $0.08 \mathrm{e} / \AA^{3}$ of the adsorption complexes $\mathrm{Pt}_{4}{ }^{*} \mathrm{C}_{6} \mathrm{H}_{6}, \mathrm{Pt}_{4}{ }^{*} 2 \mathrm{C}_{6} \mathrm{H}_{6}, \mathrm{Pt}_{4}{ }^{*} 3 \mathrm{C}_{6} \mathrm{H}_{6}$ and $\mathrm{Pt}_{4}{ }^{*} \mathrm{C}_{6} \mathrm{H}_{6}$, Table S1: Coordinates of atoms of the optimized structures in the ground state.

Author Contributions: Conceptualization, A.V.B. and L.Z.N.; methodology, A.V.B.; data curation, A.V.B.; validation, L.K.-M. and L.Z.N.; investigation, A.V.B. and L.Z.N.; formal analysis, A.V.B.; resources, A.V.B. and L.Z.N.; writing-original draft preparation, L.Z.N.; writing—review and editing, A.V.B. and L.K.-M.; visualization, A.V.B. and G.N.D.; supervision, L.K.-M.; project administration, L.K.-M. and L.Z.N.; funding acquisition, L.K.-M. All authors have read and agreed to the published version of the manuscript.

Funding: This research was funded by the Russian Science Foundation, grant number 20-19-00386.

Institutional Review Board Statement: Not applicable.

Informed Consent Statement: Not applicable.

Data Availability Statement: Data sharing is not applicable to this article.

Conflicts of Interest: The authors declare no conflict of interest. The funders had no role in the design of the study; in the collection, analyses, or interpretation of data; in the writing of the manuscript, or in the decision to publish the results.

Sample Availability: Not available.

\section{Abbreviations}

BZ: benzene; NP, nanoparticle; HAP, hyper-cross-linked aromatic polymer; HPS, hyper-crosslinked polystyrene. 


\section{References}

1. Dabbawala, A.A.; Mishra, D.K.; Hwang, J.-S. Selective hydrogenation of D-glucose using amine functionalized nanoporous polymer supported Ru nanoparticles-based catalyst. Catal. Today 2016, 265, 163-173. [CrossRef]

2. Wang, K.; Jia, Z.; Yang, X.; Wang, L.; Gu, Y.; Tan, B. Acid and base coexisted heterogeneous catalysts supported on hypercrosslinked polymers for one-pot cascade reactions. J. Catal. 2017, 348, 168-176. [CrossRef]

3. Sapunov, V.N.; Grigoryev, M.Y.; Sulman, E.M.; Konyaeva, M.B.; Matveeva, V.G. D-Glucose hydrogenation over Ru nanoparticles embedded in mesoporous hypercrosslinked polystyrene. J. Phys. Chem. A 2013, 117, 4073-4083. [CrossRef]

4. Rivas, B.L.; Pooley, S.A.; Maturana, H.A.; Villegas, S. Sorption properties of poly(styrene-co-divinylbenzene) amine functionalized weak resin. J. Appl. Polym. Sci. 2001, 80, 2123-2127. [CrossRef]

5. Demirocak, D.E.; Ram, M.K.; Srinivasan, S.S.; Kumar, A.; Goswami, D.Y.; Stefanakos, E.K. Spillover enhancement for hydrogen storage by Pt doped hypercrosslinked polystyrene. Int. J. Hydrog. Energy 2012, 37, 12402. [CrossRef]

6. Tsyurupa, M.P.; Davankov, V.A. Porous structure of hypercrosslinked polystyrene: State-of-the-art mini-review. React. Funct. Polym. 2006, 66, 768-779. [CrossRef]

7. Sulman, E.; Doluda, V.; Dzwigaj, S.; Marceau, E.; Kustov, L.; Tkachenko, O.; Bykov, A.; Matveeva, V.; Sulman, M.; Lakina, N. Catalytic properties of Ru nanoparticles introduced in a matrix of hypercrosslinked polystyrene toward the low-temperature oxidation of D-glucose. J. Mol. Catal. A Chem. 2007, 278, 112-119. [CrossRef]

8. Lyubimov, S.E.; Vasil'ev, A.A.; Korlyukov, A.A.; Ilyin, M.M.; Pisarev, S.A.; Matveev, V.V.; Chalykh, A.E.; Zlotin, S.G.; Davankov, V.A. Palladium-containing hypercrosslinked polystyrene as an easy to prepare catalyst for Suzuki reaction in water and organic solvents. React. Funct. Polym. 2009, 69, 755-758. [CrossRef]

9. Salam, N.; Mondal, P.; Mondal, J.; Roy, A.S.; Bhaumik, A.; Islam, S.M. Highly efficient base catalysis and sulfide oxidation reactions over new functionalized mesoporous polymers. RSC Adv. 2012, 2, 6464-6477. [CrossRef]

10. Dabbawala, A.A.; Sudheesh, N.; Bajaj, H.C. Palladium supported on chitosan as a recyclable and selective catalyst for the synthesis of 2-phenyl ethanol. Dalton Trans. 2012, 41, 2910-2917. [CrossRef] [PubMed]

11. Sulman, E.M.; Nikoshvili, L.Z.; Matveeva, V.G.; Tyamina, I.Y.; Sidorov, A.I.; Bykov, A.V.; Demidenko, G.N.; Stein, B.D.; Bronstein, L.M. Palladium containing catalysts based on hypercrosslinked polystyrene for selective hydrogenation of acetylene alcohols. Top. Catal. 2012, 55, 492-497. [CrossRef]

12. Salam, N.; Kundu, S.K.; Roy, A.S.; Mondal, P.; Ghosh, K.; Bhaumik, A.; Islam, S.M. A ruthenium-grafted triazine functionalized mesoporous polymer: A highly efficient and multifunctional catalyst for transfer hydrogenation and the Suzuki-Miyaura cross-coupling reactions. Dalton Trans. 2014, 43, 7057. [CrossRef] [PubMed]

13. Xu, S.; Luo, Y.; Tan, B. Recent development of hypercrosslinked microporous organic polymers. Macromol. Rapid. Commun. 2013, 34, 471-484. [CrossRef]

14. Gong, R.; Wang, W.; Huang, X.; Zhang, W.; Li, H.; Hu, C.; Tan, B. A new strategy to microporous polymers: Knitting rigid aromatic building blocks by external cross-linker. Macromolecules 2011, 44, 2410-2414.

15. Li, B.; Wang, W.; Wu, K.; Tan, B. Hypercrosslinked aromatic heterocyclic microporous polymers: A new class of highly selective $\mathrm{CO}_{2}$ capturing materials. Adv. Mater. 2012, 24, 5703-5707.

16. Li, B.; Guan, Z.; Wang, W.; Yang, X.; Hu, J.; Tan, B.; Li, T. Highly dispersed Pd catalyst locked in knitting aryl network polymers for Suzuki-Miyaura coupling reactions of aryl chlorides in aqueous media. Adv. Mater. 2012, 24, 3390-3395. [CrossRef]

17. Dawson, R.; Stöckel, E.; Holst, J.R.; Adams, D.J.; Cooper, A.I. Microporous organic polymers for carbon dioxide capture. Energy Environ. Sci. 2011, 4, 4239-4242. [CrossRef]

18. Tsyurupa, M.P.; Blinnikova, Z.K.; Davidovich, Y.A.; Lyubimov, S.E.; Naumkin, A.V.; Davankov, V.A. On the nature of "functional groups" in non-functionalized hypercrosslinked polystyrenes. React. Funct. Polym. 2012, 72, 973-982. [CrossRef]

19. Davankov, V.A.; Tsyurupa, M.P. Structure and properties of hypercrosslinked polystyrene-the first representative of a new class of polymer networks. React. Polym. 1990, 13, 27-42. [CrossRef]

20. Bronstein, L.M.; Matveeva, V.G.; Sulman, E.M. Nanoparticles and Catalysis; Astruć, D., Ed.; Wiley: Hoboken, NJ, USA, 2007; pp. 93-127.

21. Bronstein, L.M. Encyclopedia of Nanoscience and Nanotechnology; Nalwa, H.S., Ed.; American Scientific Publishers: Stevenson Ranch, CA, USA, 2004; Volume 7, pp. 193-206.

22. Nemygina, N.; Nikoshvili, L.; Bykov, A.; Sidorov, A.; Molchanov, V.; Sulman, M.; Tiamina, I.; Stein, B.; Matveeva, V.; Sulman, E.; et al. Catalysts of Suzuki cross-coupling based on functionalized hyper-cross-linked polystyrene: Influence of precursor nature. Org. Process. Res. Dev. 2016, 20, 1453-1460. [CrossRef]

23. Nikoshvili, L.; Bakhvalova, E.S.; Bykov, A.V.; Sidorov, A.I.; Vasiliev, A.L.; Matveeva, V.G.; Sulman, M.G.; Sapunov, V.N.; KiwiMinsker, L. Study of deactivation in Suzuki reaction of polymer-stabilized Pd nanocatalysts. Processes 2020, 8, 1653. [CrossRef]

24. Eremin, D.B.; Ananikov, V.P. Understanding active species in catalytic transformations: From molecular catalysis to nanoparticles, leaching, "cocktails" of catalysts and dynamic systems. Coord. Chem. Rev. 2017, 346, 2-19. [CrossRef]

25. Galushko, A.S.; Gordeev, E.G.; Kashin, A.S.; Zubavichus, Y.V.; Ananikov, V.P. Visualization of catalyst dynamics and development of a practical procedure to study complex "cocktail"-type catalytic systems. Faraday Discuss. 2021, 229, 458-474. [CrossRef]

26. Polynski, M.V.; Ananikov, V.P. Modeling key pathways proposed for the formation and evolution of "cocktail"-type systems in Pd-catalyzed reactions involving ArX reagents. ACS Catal. 2019, 9, 3991-4005. [CrossRef] 
27. Prima, D.O.; Kulikovskaya, N.S.; Galushko, A.S.; Mironenko, R.M.; Ananikov, V.P. Transition metal 'cocktail'-type catalysis. Curr. Opin. Green Sustain. Chem. 2021, 31, 100502. [CrossRef]

28. Chen, L.-W.; Hao, Y.-C.; Guo, Y.; Zhang, Q.; Li, J.; Gao, W.-Y.; Ren, L.; Su, X.; Hu, L.; Zhang, N.; et al. Metal-organic framework membranes encapsulating gold nanoparticles for direct plasmonic photocatalytic nitrogen fixation. J. Am. Chem. Soc. 2021, 143, 5727-5736. [CrossRef] [PubMed]

29. Xie, K.; An, N.; Zhang, Y.; Liu, G.; Zhang, F.; Zhang, Y.; Jiao, F. Two-dimensional porphyrin sheet as an electric and optical sensor material for $\mathrm{pH}$ detection: A DFT study. Comput. Mater. Sci. 2020, 174, 109485. [CrossRef]

30. McCormick, T.M.; Bridges, C.R.; Carrera, E.I.; DiCarmine, P.M.; Gibson, G.L.; Hollinger, J.; Kozycz, L.M.; Seferos, D.S. Conjugated polymers: Evaluating DFT methods for more accurate orbital energy modeling. Macromolecules 2013, 46, 3879-3886. [CrossRef]

31. Okumura, M.; Kitagawa, Y.; Kawakami, T. DFT calculations for the heterojunction effect between metal clusters and the stabilizer molecules. Int. J. Quantum Chem. 2010, 110, 2903-2911. [CrossRef]

32. Okumura, M.; Sakata, K.; Tada, K.; Yamada, S.; Okazaki, K.; Kitagawa, Y.; Kawakami, T.; Yamanaka, S. DFT Calculations of the Heterojunction Effect for Precious Metal Cluster Catalysts. Prog. Theor. Chem. Phys. 2012, 26, 363-375.

33. Ni, M.; Zeng, Z. Density functional study of hydrogen adsorption and dissociation on small Pdn (n = 1-7) clusters. J. Mol. Struct. 2009, 910, 14-19. [CrossRef]

34. Kalita, B.; Deka, R.C. Density Functional Studies on Structure and Reactivity of Pdn Clusters for n=1-13. Bull. Catal. Soc. India 2006, 5, 110-120.

35. Yudanov, I.V.; Genest, A.; Schauermann, S.; Freund, H.-J.; Roösch, N. Size dependence of the adsorption energy of CO on metal nanoparticles: A DFT search for the minimum value. Nano Lett. 2012, 12, 2134-2139. [CrossRef]

36. Lacaze-Dufaure, C.; Roques, J.; Mijoule, C.; Sicilia, E.; Russo, N.; Alexiev, V.; Mineva, T. A DFT study of the NO adsorption on $\mathrm{Pd}_{\mathrm{n}}(\mathrm{n}=1-4)$ clusters. J. Mol. Catal. A 2011, 341, 28-34. [CrossRef]

37. Cortese, R.; Schimmenti, R.; Armata, N.; Ferrante, F.; Prestianni, A.; Duca, D.; Murzin, D.Y. Investigation of polyols adsorption on $\mathrm{Ru}, \mathrm{Pd}$ and Re using vdW density functionals. J. Phys. Chem. C 2015, 119, 17182-17192. [CrossRef]

38. Ferrante, F.; Prestianni, A.; Duca, D. Computational investigation of alkynols and alkyndiols hydrogenation on a palladium cluster. J. Phys. Chem. C 2014, 118, 551-558. [CrossRef]

39. Prestianni, A.; Crespo-Quesada, M.; Cortese, R.; Ferrante, F.; Kiwi-Minsker, L.; Duca, D. Structure sensitivity of 2-methyl-3-butyn2-ol hydrogenation on Pd: Computational and experimental modeling. J. Phys. Chem. C 2014, 118, 3119-3128. [CrossRef]

40. Prestianni, A.; Ferrante, F.; Sulman, E.M.; Duca, D. DFT investigation on the nucleation and growth of small palladium clusters on a hypercrosslinked polystyrene matrix. J. Phys. Chem. C 2014, 118, 21006-21013. [CrossRef]

41. Cruz, M.T.d.; Carneiro, J.W.d.; Aranda, D.A.G.; Bühl, M. Density functional theory study of benzene adsorption on small Pd and Pt clusters. J. Phys. Chem. C 2007, 111, 11068-11076. [CrossRef]

42. Carvajal, E.; Hahn-Herrera, O.; Orgaz, E. Density functional investigation of silver, palladium and silver-palladium small sized clusters. Rev. Mex. Fis. 2009, 55, 418-424.

43. Liu, W.; Ruiz, V.G.; Zhang, G.-X.; Santra, B.; Ren, X.; Scheffler, M.; Tkatchenko, A. Structure and energetics of benzene adsorbed on transition-metal surfaces: Density-functional theory with van der Waals interactions including collective substrate response. New J. Phys. 2013, 15, 053046. [CrossRef]

44. Tysoe, W.T.; Ormerod, R.M.; Lambert, R.M.; Zgrablich, G.; Ramirez-Cuesta, A. Overlayer structure and kinetic behavior of benzene on palladium(111). J. Phys. Chem. 1993, 97, 3365-3370. [CrossRef]

45. Canduela-Rodriguez, G.; Sabbe, M.K.; Reyniers, M.-F.; Joly, J.-F.; Marin, G.B. Thermodynamic study of benzene and hydrogen coadsorption on Pd(111). Phys. Chem. Chem. Phys. 2014, 16, 23754-23768. [CrossRef]

46. Davis, J.B.A.; Horswell, S.L.; Piccolo, L.; Johnston, R.L. Computational study of the adsorption of benzene and hydrogen on palladium-iridium nanoalloys. J. Organomet. Chem. 2015, 792, 190-193. [CrossRef]

47. Yildirim, H.; Greber, T.; Kara, A. Trends in adsorption characteristics of benzene on transition metal surfaces: Role of surface chemistry and van der Waals interactions. J. Phys. Chem. C 2013, 117, 20572-20583. [CrossRef]

48. Neese, F. The ORCA program system. WIREs Comput. Mol. Sci. 2012, 2, 73-78. [CrossRef]

49. Neese, F. Software update: The ORCA program system, version 4.0. WIREs Comput. Mol. Sci. 2017, 8, e1327. [CrossRef]

50. Weigend, F.; Ahlrichs, R. Balanced basis sets of split valence, triple zeta valence and quadruple zeta valence quality for $H$ to Rn: Design and assessment of accuracy. Phys. Chem. Chem. Phys. 2005, 7, 3297-3305. [CrossRef] [PubMed] 